\title{
'What is the Purpose of Feedback when Revision is not Expected?' A Case Study of Feedback Quality and Study Design in a First Year Master's Programme
}

\author{
Olga Dysthe \\ University of Bergen, Norway
}

\begin{abstract}
This article presents a qualitative case study of feedback practices in the first year of a two-year master's programme. Writing and feedback are viewed as contextualized cultural practices shaped by factors at macro, meso and micro level. The empirical data consists of a text corpus of students' essays and teachers' comments, supplemented by interviews. Initial findings showed a discrepancy between the considerable amount of comments given by the teachers and the students' lack of use of the feedback they received. The text analysis, based primarily on Hattie and Timperley's (2007) model of feedback revealed several features of the feedback that counteracted learning, but a major problem was unclear goals for the writing combined with a study design that did not include revision of student texts.
\end{abstract}

\section{Introduction}

More resources are spent on feedback and less on lecturing in Norwegian universities after a reform of Higher Education in 2002. It is, therefore, crucial to find out whether students use the feedback they receive, how they use it, and if they do not use it, why not. Given the existing research evidence of the importance of feedback for students' learning (Black and Wiliam 1998, Hattie and Timperley 2007 and Shute 2008), such questions are relevant in all countries. Surprisingly, the problem of why feedback is not used by students has received relatively little attention in the research literature.

Norway has been an active partner in the European Bologna Process, and the implementation of the Quality Reform aligned our system to the European norm: a three year bachelor's degree, plus twoyear master's, plus three-year PhD. ${ }^{1}$ For Norway this meant a one-year reduction in bachelor's degree and the modularization of all study programmes. Most modules or courses are 15-20 ECTS ${ }^{2}$. The Quality Reform was also a pedagogical reform aimed at more effective learning, for instance by introducing more writing, better feedback and new assessment forms (Dysthe 2009). A pedagogical reform was needed because too many students failed, dropped out or spent too long finishing, and because of the need to maintain the quality of the shortened bachelor's degree. A two-year master's programme has always been the Norwegian norm, but the expectations of finishing on time became stronger. A major stumbling block for most master's students was insufficient experience in academic writing, and this was the rationale behind the introduction of compulsory writing assignments in all courses.

The first year of the Master's of Education Programme consists of four courses, and the second of research and thesis writing. This study investigates feedback in the course 'Educational Philosophy'

\footnotetext{
${ }^{1}$ For a comparison of some pedagogical aspects of the Bologna Process in Norway and Germany, see Dysthe and Webler (2010).

${ }^{2}$ ECTS: European Credit System
} 
(semester 1) and 'Research Methods' (semester 2). The two courses were structured around five carefully planned compulsory writing assignments in each course. Students posted their texts and got electronic feedback from a professor or an experienced tutor (all called 'teachers'). The assignments were designed with the double purpose of writing-to-learn course content, and learning-to-write academic papers. These key terms originate in WAC (Writing Across the Curriculum) and WID (Writing In the Disciplines), which have influenced writing in higher education for many decades (Bazerman and Russell, 1994, Bean 1996, Britton 1970, Emig 1977, Fulwiler and Young 1982, Mcleod and Sovern 2006 and Walvoord and McCarthy 1990). Although Norwegian universities have had no formal WAC/WID programmes, the ideas and practices have been a major source of inspiration for development work. ${ }^{3}$

The overarching research question in this study is: How is student learning from feedback afforded or constrained by the writing and feedback practices in a first year Master's programme? The subquestions focus on three aspects: 1) Feedback quality 2) Students' use of feedback 3) Students' learning from feedback. The purpose of the study was to gather knowledge in order to improve the teaching and learning environment. Even though the findings from such a small study cannot be generalized, they point towards crucial factors relevant across institutions and countries.

\section{Materials and Methods}

This study combined text analysis and student interviews. The primary data source consisted of student essays and teacher feedback texts posted in the Virtual Learning Environment, a text corpus of approximately 70 pages. Teacher feedback consisted of margin comments plus 1-2 page end comments. The selection of student texts was made by the teachers. As a researcher, I read a wider set of papers in order to check the representativeness of the selected texts. Study plans combined with assignments and teacher guidelines provided information about the design and content of the courses and background information needed to analyse student and teacher texts. A focus group interview with four of the students gave insight into student reaction to the processes and their selfreported learning. The informants were chosen by the programme coordinator to represent variation. The session lasted one and a half hours and was taped and transcribed by a research assistant. Careful considerations were given to the ethical dilemmas involved in handling material from colleagues and students and decisions agreed on with all participants.

The analysis of the feedback texts was based on a model presented by Hattie and Timperley (2007) which since then has become quite well known internationally. I chose this model because it is based on both theory and metastudies of feedback research. Hattie and Timperley see the main purpose of feedback as reducing discrepancies between the student's understandings and performance and a goal. Effective feedback must therefore answer three questions: Where am I going? (goals), How am I going? (progress towards the goal), and Where to next? (needed activities and action to improve). Such 'feed up', 'feed back' and 'feed forward' are important not only on task level but also on process level, self-regulation and self level (Hattie and Timperley, 2007: 86-87). This model was constructed to help teachers improve their feedback practices, but I used it as an analytical tool, supplemented by categories that emerged through iterative readings of transcripts.

The text analysis involved several layers. The first consisted of reading and analysis of all student texts and feedback. The second layer of analysis was to consider all feedback texts written by one teacher in order to develop a 'profile' of each feedback provider (not presented here). The third layer was to compare the profiles in order to identify productive and unproductive feedback practices.

\section{Presentation of Findings}

Hattie and Timperley's model focuses on goals, feedback on the students' performance, and on advice and challenges given to help the students improve. There is general agreement among

\footnotetext{
${ }^{3}$ In a research study of the German university seminar tradition, Kruse (2006) discovered that writingto-learn was also an important part of Humboldtian pedagogy from the $19^{\text {th }}$ century.
} 
feedback researchers that these three elements are crucial to feedback quality (Shute 2008), even though the words used to describe them may vary.

\section{Feedback quality}

An overarching finding was that the teachers were very conscientious feedback providers and wrote many and long comments on student texts. But even though most of the teachers were very experienced, the quality of the feedback differed widely. Three major quality problems were identified, the first of which was rooted in the formulation of the assignments.

\section{Lack of engagement with goals}

In the context of the two courses, 'goals' may mean the overarching purpose of student writing in the course, or more restricted goals relating to genre and content expectations of the specific assignment. Only two teacher comments explicitly dealt with the goal of the writing assignment: 'You have reformulated the assignment and answered something else'. Here the teacher seems to have a clear idea of the goal of the assignment, which the student has not met. Another teacher formulated a goal for the writing in his comment to a student: '[...] to develop analytical lenses, not to find the correct answer, but to be more reflective regarding your own and others' points of view'. Further analysis revealed that the goals of the writing assignments were unclear.

For writing teachers it is rather obvious that students need to know what kind of genre to write in, but for teachers in the disciplines this may not be so obvious. The genre expectations were not discussed in class and not made clear in the assignments, as the following examples show: 'Discuss how different forms of knowledge are represented in formal education'; 'Use the literature as support and argue for pedagogy as a) practical discipline, b) a theoretical discipline'; 'Use your own experiences as a point of departure for a text about the value of education. Use literature as support'. In the first assignment a discussion is asked for; in the second argumentation, while in the third the genre choice is left to the student. Feedback comments indicated, however, that a 'full-blown' academic paper was the norm used to evaluate student performance, as the lack of introduction, problem statement or conclusion were often pointed out as weaknesses.

\section{Feedback given primarily on performance - little explicit feed-forward}

The second finding related to what Hattie and Timperley call 'task level'. The analysis showed that the great majority of teacher comments could be categorised as 'feedback on performance' and very few as explicit feed-forward. Common types of deficiencies identified in the feedback were: 1. Inadequate referencing, 2. Language problems, 3. Lack of precision, 4. Lack of argumentation, 5. Voice ('Who talks in the text - you or the literature?').

Vines' (2009) distinction between affirmative, evaluative and challenging feedback proved useful in the analysis. Affirmative feedback may be 'ritual praise' ('I have read your text with great interest', 'Good work') or 'specific praise' ('Clear introduction', 'Your example functions well', 'Good transition'). Previous studies have shown that while ritual praise is hardly noticed by students and is of little value, specific praise is important, signalling: Do more of this in the future. Both types of affirmative feedback were found. Evaluative comments that were critical and often quite specific dominated, however: 'Too much repetition of literature and too little understanding'; 'You do not differentiate between analysis and interpretation'; 'It is not clear what stand you take yourself'. A few examples of explicit feedforward were found, for instance: 'Formulate your own controlling questions'; 'Present your own viewpoint'; 'Use examples'. Explicit feed-forward was rare, however, and an important question is, therefore, whether evaluative comments may function as feed-forward. In some cases this is clearly the case. When the teacher writes, 'Your conclusion is common sense' the implicit feed-forward is that the student needs to revise and make the conclusion less commonsensical. The problem with implicit feed-forward is that it does not contain any clues for the student about how to go about improving the text.

Why was explicit feed-forward so rare? One reason may be teacher belief that criticism is easier to take when it is indirect; another that students at master's level should not be told what to do but find their own way. The most likely reason was, however, that the study design did not include revision and teachers, therefore, omitted specific advice. In the interviews, students nevertheless expressed their need for explicit feed-forward. 


\section{Lack of attention to process and self regulation in feedback}

Another finding related to Hattie and Timperley's four levels was a lack of attention to processes and to self regulation. Given the study design with no demands on revision, this result is somewhat surprising. To establish effective writing strategies and make students reflect on what made them better writers would be reasonable long-term goals for feedback in such a setting. One explanation may be that the teachers had their focus on content knowledge, not on writing pedagogy and were unable to spot ineffective work strategies or habits that might inhibit students' improvement of their writing skills.

\section{Importance of dialogic engagement, challenge and confrontation}

Although not specifically addressed in the Hattie and Timperley model, dialogic engagement combined with challenge and confrontation emerged as strong characteristics of the 'good feedback' in student interviews. This has been found in several studies in higher education (Rogers (forthcoming) and Dysthe et al. (2011). Clear differences were identified in the teachers' feedback style; for instance, between what I have chosen to call a 'teaching style' of feedback and a 'dialogical, personal and challenging style'. The 'teaching style' is characterised by impersonal statements which address the problems of the text indirectly and by 'lecturing', often at considerable length. Examples of introduction to such 'lectures': 'Qualitative research is sometimes criticised for [...]'; 'Harding claims that [...]'; 'Validity has to do with [...]'. Students reacted very negatively to this kind of feedback and preferred a personal and dialogic feedback style, often signalled in these texts by phrases like, 'In my view [...]'; 'what do you think?'; 'I think [...] - but you may disagree'. If this becomes just formulaic, it does not challenge the student, but these kinds of comments were often combined with clear challenges; for instance, 'Where is the cultural and historical background for this?', 'I am not convinced by your argument here'. The interviewed students agreed that challenges, disagreements and contradictions forced them to think, but in order to accept the challenge in a positive way, a personal engagement from the teacher was crucial.

\section{Students' use of feedback}

Students may use feedback for different purposes: 1) for motivation (to work harder), 2) to improve the work and show direction for future learning, 3) to initiate reflection (seeing things in a new light), and 4) to understand disciplinary expectations and quality standards (Orsmond, Merry and Reiling 2005). These authors concluded that use of feedback is a skill that needs to be taught. There are some studies on students' use of feedback in particular courses (Crisp 2007, Duncan 2007 and Ellery 2008). The need to look at the 'feedback loop' and the wider context is highlighted by Hounsell et al. (2008). By looking at the interrelated steps in the feedback loop it was possible to identify the trouble spots which could spoil otherwise good feedback activities.

The simple answer to the question of how students in this study used feedback, is that they did not use it, and a major 'trouble spot' was the lack of space for revision in the study design. Students recognised this as a problem: 'I found it very frustrating that the study design prevented revision. As I see it, revision is crucial for improvement of academic writing'. The text analysis revealed that the same writing problems surfaced again and again in many of the students' papers, and a major reason why students did not learn from the feedback was that they did not revise. Students only registered the gap in their knowledge or skills but did not close it. Understanding what is wrong is not sufficient; students have to practice in order to learn. This commonplace insight about learning from feedback is too often disregarded in higher education.

The more complex answer is that even though transfer to the next paper was difficult, students did benefit from the feedback. Dialogic feedback had a particularly motivating effect and made students more reflective. One student, however, made an interesting comment relating to the difference in feedback for immediate revision and for later use:

When students are not asked to revise, this makes new demands on the teacher. The feedback has to be different. He needs to be very conscious of how comments can be transferred and comment more on 'what to do next time' than how to improve this text. It is actually a question of different ways of giving feedback.

This raises the unexplored question of what constitutes effective feedback when revision is not expected. In writing courses, immediate revision after feedback is taken for granted, but in disciplinary 
courses it is not unusual that feedback is provided at a time or in a context when revision is not possible. $^{4}$

\section{The study design and student learning}

One of the pedagogical ideas behind the study design of this master's programme was to involve students actively in the curriculum through writing and feedback. The five writing assignments dealt with central aspects of the curriculum. The overarching purpose was twofold: engagement with the curriculum content (writing-to-learn) and learning how to write about educational issues. The interviewed students realised the difficulties in accommodating both goals:

I see the dilemma in this study programme. The basic idea is to train independence and the assignments were designed to help us find out things on our own. If revisions were demanded they would have to reduce the number of assignments. And I thought that even 5 assignments did not cover the major parts of the curriculum. And at the same time we need to work more on each assignment to improve our writing.

Five assignments seemed to be a minimum in order to make students engage with major parts of the curriculum. A reduction to three (with space for revision), would make it less effective as a writing-tolearn course, but more effective for learning to write an academic paper. The study design was thus a compromise that reduced student learning for both purposes.

\section{Discussion and Implications}

\section{The importance and limitations of clear goals}

There is consensus in the feedback literature that clear goals are important for both students and teachers. The problem with vague goals is that students do not know how to attain them or when they miss them. In this study students were confused because their writing was to serve both 'writing-tolearn-to-write' and 'writing-to-learn' purposes. The question is whether these goals can be combined.

Mastering the art and craft of academic writing involves sub-goals relating to structure, logical argument, use of sources, referencing and precise language; all of which are rarely in focus in writingto-learn assignments. Demonstrating disciplinary understanding and being able to present different perspectives and arguments in the literature, however, are shared goals. 'Writing-to-learn' assignments in the disciplines are usually more open-ended, exploratory and have less formal goals and criteria than traditional writing assignments. To the extent that feedback is given on such assignments, they are not focused on performance but on motivating students to a deeper understanding of, and reflection on, course contents. Thus it could be argued that feedback on 'writing-to-learn' assignments is a different feedback genre from the one behind Hattie and Timperley's model of feedback.

The findings in this study highlight the need to be clear about the difference in goals and purpose of writing-to-learn and learning-to-write assignments. They can be accommodated in the same course, but each assignment should focus primarily on one, and expectations for each assignment should be discussed with the students.

\section{Task level feedback needs to be supplemented with focus on process and self regulation}

A major finding in the study was that almost all comments were on task level and that there were too many. Research studies have shown that too much feedback at this level may detract from performance (Shute 2008). In the context of no revision it is particularly interesting that feedback about the task does not easily transfer to other tasks:

\footnotetext{
${ }^{4}$ A study of feedback practices at a university in England showed that a very comprehensive feedback system was in place, but feedback was only given on students' papers after the final exam (Havnes 2008). Then feedback functioned more as legitimization of the marks given than help to improve. The study showed that only $20 \%$ of the students picked up the feedback sheets, indicating that students recognized this and did not expect to learn from the comments or did not care.
} 
[Task feedback] is more powerful when it is about faulty interpretations, not lack of information. If students lack necessary knowledge, further instruction is more powerful than feedback information. One of the problems with feedback at the task level is that it often does not generalize to other tasks. Thompson (1998), for example, demonstrated that improvement was specific to the questions for which feedback was provided and was not used to answer other questions' (Hattie and Timperley 2007: 91).

Feedback at the process level, however, is more easily transferable to other situations. The term 'process' is used for a wide variety of strategies and ways of organising, studying and working in order to learn and develop. Attending to the phases of the writing process is one example, but strategies for error detection, for rejecting false hypotheses and for trying out new ways of solving problems, are other examples. Feedback that helps the student's awareness of more effective strategies can have a long-term effect and carry over to subsequent assignments.

The importance of self-regulation for learning in general is well established. Kluger and DeNisi (1996) concluded that the effectiveness of feedback is dependent on student self-regulation, for instance their ability to self assess and their willingness to invest effort and commitment in the task. In higher education, there has generally been too little attention to how feedback can promote self assessment, self efficacy and student commitment.

This study has shown that Hattie and Timperley's model is a useful reminder for feedback providers. Instead of telling students primarily what is lacking, and thus implicitly referring to norms and criteria, teachers should focus more on explicit feed-forward. If immediate revision is not expected, it is even more important to give feedback on the process and self-regulation level, and not just on the task.

In this article the focus has been both on the micro and meso level of the teaching and learning system, i.e. the feedback provided by teachers, and on study design. One implication of this study is the necessity to consider carefully how teacher feedback on writing can be improved. In this respect the study adds to existing feedback literature which mainly deals with the micro level. The most important implication for future practice, however, is the importance of the study design for students' use of feedback for learning. Improvements at the micro level may not have much effect if counteracted by the study design. On the other hand, there is also a need for further study of what kind of feedback on writing is most productive for learning when revision is not expected. 


\section{References}

Bazerman, C. and Russell, D. (1994) Landmark Essays in Writing across the Curriculum. Davis: Hermagoras Press

Bean, J. (1996) Engaging Ideas: The Professor's Guide to Integrating Writing, Critical Thinking, and Active Learning in the Classroom. San Francisco: Jossey-Bass

Black, P. and Wiliam, D. (1998) 'Assessment and classroom learning'. Assessment in Education 5 (1), 7-75

Britton, J. (1970) Language and Learning. London: Penguin

Crisp, B. R. (2007) 'Is it worth the effort? How feedback influences students' subsequent submission of assessable work'. Assessment and Evaluation in Higher Education 32 (5), 571-581

Duncan, N. (2007) '"Feed-forward": improving students' use of tutor's comments'. Assessment and Evaluation in Higher Education 32 (3), 271-283

Dysthe, O. (2009) 'What factors influence the improvement of academic writing practices? A study of reform of undergraduate writing in Norwegian higher education'. in Traditions of Writing Research. ed. by Bazerman, C., Krut, R., Lunsford, K.J., Null, S., Rogers, P.M., and Stansell, A. New York: Routledge

Dysthe, O., Lillejord, S., Vines, A., and Wasson, B. (2011) 'Productive E-feedback in Higher Education - Some Critical Issues'. In Learning Across Sites: New Tools, Infrastructures and Practices. ed. by Ludvigsen, S., Lund, A., Rasmussen, I. and Säljö, R. Oxford U: Pergamon Press, 243258

Dysthe and Webler (2010) 'Pedagogical Issues from Humboldt to Bologna. The Case of Norway and Germany'. Higher Education Policy 23, 247-270

Ellery, K. (2008) 'Assessment for learning: A case study using feedback effectively in an essay-style text'. Assessment and Evaluation in Higher Education 33 (4), 421-429

Emig, J. (1977) 'Writing as a Mode of Learning.' College Composition and Communication 28, $122-$ 128

Fulwiler, T. and Young, A. (eds.) (1982) Language Connections: Writing and Reading across the Curriculum. Urbana: NCTE

Hattie, J. and Timperley, H. (2007) 'The Power of Feedback'. Review of educational research 77 (1), $81-112$

Havnes, A. (2008) 'There is a Bigger story behind it: an analysis of mark average variation across programmes'. 'EARLI/Northumbria Assessment Conference'. held 27-29 August 2009 at Potsdam. London: Elsevier

Hounsell, D., McCune, V., Hounsell, J. and Litjens, J. (2008) 'The quality of guidance and feedback to students'. Higher Education Research and Development 27 (1), 55-67

Kluger, A. N. and DeNisi, A. (1996) 'The effect of feedback interventions on performance: A historical review, a meta-analysis, and a preliminary feedback intervention theory'. Psychological Bulletin 119 (2), 254-284

McLeod, S. and Sovern, I. (eds.) (2006) Composing a Community: A History of Writing Across the Curriculum. West Lafayette: Parlor Press 
Kruse, O. (2006) 'The origins of writing in the discipline. Traditions of seminar writing and the Humboldtian ideal of the research university'. Written Communication 23 (3), 331-352

Orsmond, P., Merry, S. and Reiling, K. (2005) 'Biology students' utilization of tutor's formative feedback: a qualitative interview study'. Assessment and Evaluation in Higher Education 30 (4), 369-386

Rogers, P.M. (forthcoming) 'Developing writers: From feedback and response to dialogic interaction'. Research in the Teaching of English.

Shute, V. J. (2008) 'Focus on formative feedback'. Review of Educational Research 78 (1), 153-189

Vines, A. (2009) 'Multivoiced e-feedback in the study of law: Enhancing learning opportunities?' In Learning in the Network Society and the Digitized School. ed. by Krumsvik, R. New York: Nova Science

Walvoord, B. and McCarthy, L. (1990) Thinking and Writing in College: A Naturalistic Study in Four Disciplines. Urbana: National Council of Teachers of English 